\title{
31. MEASUREMENTS OF THERMAL CONDUCTIVITY
}

\author{
E.R. Oxburgh and D. Griffiths, \\ Department of Geology and Mineralogy, Oxford University, Oxford, U.K.
}

The thermal properties of the igneous part of the oceanic crust, although not well known, are important for understanding a number of large- and small-scale thermal processes affecting the evolution of oceanic crust. The igneous rocks of the crust are highly heterogeneous in their physical properties, which are determined by their original chemical and mineralogical composition, rock texture, porosity, and subsequent diagenetic or metamorphic changes.

We report herein measurements of thermal conductivity on 11 porous basalts (Table 1). To conserve material and because of the general desirability of making as many different measurements as possible on the same sample, the samples tested were those which previously had been used for the measurements of electrical conductivity (Chroston et al., this volume).

Measurements were made in a conventional divided-bar apparatus (Birch, 1950) calibrated against a gem-quality quartz standard cut normal to the c-axis and taken to have a thermal conductivity of $14.80 \mathrm{CU}{ }^{1}$ Intermediate standards of polycarbonate (lexan) were used above and below the sample, and these were regularly checked against quartz. The temperature difference across the samples was about $7^{\circ} \mathrm{C}$, and the mean sample temperature varied from $23^{\circ}$ to $27^{\circ} \mathrm{C}$ in different runs. Measurements were made under axial loading of about 100 bars, to ensure good thermal contact. All samples had been kept in seawater and were measured in a saturated condition.

The accuracy of the divided-bar method is very sensitive to departures from orthogonal, radially symmetrical geometry in the samples measured. This is particularly so when the samples are relatively small, as in the present case $(0.75$ in. diameter and 0.5 to 0.8 in. long). We encountered considerable difficulty in preparing samples of suitable quality, because of disaggregation and splitting during lapping. For this reason, and because some samples split under axial compression while measurements were being made, results are available for only seven of the samples studied (Table 1). We do not know whether these difficulties arose from the intrinsic

${ }^{1} \mathrm{CU}=$ conductivity unit $=10-{ }^{3} \mathrm{Cal} / \mathrm{cm} \mathrm{sec}{ }^{\circ} \mathrm{C}$.
TABLE 1

Results of Thermal Conductivity Measurements

\begin{tabular}{lc}
\hline $\begin{array}{c}\text { Sample } \\
\text { (Interval in cm) }\end{array}$ & $\begin{array}{c}\text { Thermal Conductivity } \\
\left(\mathrm{mCal} / \mathrm{cm} \mathrm{sec}^{\circ} \mathrm{C}\right)\end{array}$ \\
\hline $407-36-3,80-82$ & 2.98 \\
$407-38-2,140-142$ & 3.55 \\
$407-42-1,69-71$ & 3.73 \\
$407-38-3^{\mathrm{a}}$ & 2.92 \\
$407-39-2,60-62$ & $\mathrm{~b}$ \\
$407-46-2,42-44$ & 2.52 \\
$408-36-1,98-100$ & $\mathrm{~b}$ \\
$408-37-1,125-130$ & 2.63 \\
$408-38-2,20-25$ & $\mathrm{~b}$ \\
$409-9-3,136-138$ & 2.72 \\
$412 \mathrm{a}-3-2,77-80$ & $\mathrm{~b}$ \\
\hline \multicolumn{2}{c}{} \\
anformation not on sample container. \\
bSample disaggregated during preparation or \\
measurement.
\end{tabular}

properties of the rock, or whether the material had been weakened by the cycling of temperature and pressure to which it had been subjected during the previous electrical conductivity measurements.

There is a wide range in the values of thermal conductivity for basalt reported in the literature and measured in our laboratory; values range from 3 to $6 \mathrm{CU}$. This variation is largely attributable to variation in porosity. The present results lie close to the lower limit of this range. They may be reasonably representative of the uppermost part of Layer 2, but thermal conductivity would be expected to increase rapidly with depth as porosity diminished and density increased. Many more measurements are required for the adequate characterization of Layer 2, and these measurements should be made on larger samples.

\section{REFERENCE}

Birch, F., 1950. Flow of heat in the Front Range Colorado, Bulletin of the Geological Society of America, v. 61, p. 567. 